\title{
Dynamics and effects of Ligula intestinalis (L.) infection in the native fish Barbus callensis Valenciennes, 1842 in Algeria
}

\author{
Sonia Ould Rouis ${ }^{1 *}$, Abdelhalim Ould Rouis ${ }^{1}$, Henri J.Dumont2,4, Kit Magellan ${ }^{3}$ and Abdeslem Arab ${ }^{1}$ \\ ${ }^{1}$ Faculty of Biological Sciences (FSB), Department of Ecology and Environment, Laboratory of Dynamic and Biodiversity, University of \\ Science and Technology Houari Boumediene (USTHB) BP 32, El Alia Bab-Ezzouar 16111 Algiers, Algeria; \\ ${ }^{2}$ Department of Biology, Limnology Section, Ghent University, Ledeganckstraat 35, Ghent, B-9000, Belgium; \\ ${ }^{3}$ South African Institute for Aquatic Biodiversity, Grahamstown 6139, South Africa; \\ ${ }^{4}$ Department of Ecology and Institute of Hydrobiology, Jinan University, Guangzhou 510632, China
}

\begin{abstract}
The dynamics of the emergence, duration, and decline phases in epizootic cycles are well known for humans and some crops, but they are poorly understood for host-parasite systems in the wild. Parasites may be particularly insidious as they are often introduced unintentionally, simultaneously with their hosts, and later transferred to species in the new location. Here we investigate the epizootic dynamics of the tapeworm Ligula intestinalis in the Hamiz reservoir, Algeria, and explore its effects on the cyprinid fish Barbus callensis. Regular sampling was conducted from October 2005 to February 2008 with intermittent surveys carried out until 2010. Five percent of the 566 specimens of $B$. callensis that were caught were infected, with the maximum number of parasites found in spring. There was no obvious difference in weight between uninfected fish and infected ones, and infection did not affect fish condition. However, infected fish were significantly longer than uninfected fish and had inhibited gonad development. The proportion of infected fish caught was significantly higher in year 1 and by the second winter, infection collapsed to zero. The Ligula infection thus appeared to have minimal ecological effects and be of a temporary nature, thus exhibiting an epizootic cycle. Taken together, our data indicates that this infection declined or even failed during our study period. Failure may be due to the specific genetic strain of Ligula, but invasive carp may also have been influential in both the introduction and subsequent decline of this parasite.
\end{abstract}

\section{Keywords}

Ligula intestinalis, epizootics, cyprinid fish, infection parameters, North Africa

\section{Introduction}

The dynamics of the emergence, duration, and decline phases in epizootic cycles are well known for humans and some crops, but they are poorly understood for host-parasite systems in the wild (Heins et al. 2011). Introduced species, such as some animals and pathogens, may result in changes to community assembly (Dunn et al. 2012), modify the physical structure of habitats, impact on resident species (Simberloff and Rejmánek 2010; Simberloff et al. 2013) and contribute to ecosystem degradation and impairment of ecosystem services worldwide (Pyšek and Richardson 2010). However, not all introductions are successful. Many introductions may occur, but individuals subsequently fail to spread or reproduce (Richardson et al. 2000; Pyšek and Richardson 2010). Unfortunately, the mechanisms of success or failure of introductions, particularly those for host-parasite systems, often remain enigmatic.

Parasites are usually added unintentionally, simultaneously with their hosts, which can induce rapid species loss in favor of the introduced host species (Bouzid et al. 2013), cause often significant consequences for host biology (Barber et al. 2000) and impact freshwater ecosystems (Kennedy 1993). Native parasites in general represent a significant proportion of aquatic biomass (Yen Nhi et al. 2013) and introduced parasites may be particularly insidious. Once introduced, parasites can be lost, transferred, or gained by other members of the freshwater community in the new location (Lafferty et al. 2010). Numerous effects of parasites have been studied. Changes in foraging efficiency, time budget, habitat selection, competitive ability, predator-prey relationships, swimming 
performance and sexual behaviour and mate choice have all been associated with, and in some cases been shown to be a result of, parasite infections (Barber et al. 2000). Parasites may also affect fish reproduction depending on the targeted organ (Sitjà-Bobadilla 2009) and damage to reproductive organs may pose a threat to the survival of the host species (SitjàBobadilla 2008). Parasites may thus induce net fitness effects on individual hosts resulting from the direct effects of infection (which are usually negative) combined with the consequences of indirect effects on other species (which may be positive or negative) (Dunn et al. 2012). Studies of parasite infections in alien host species and the native species that may be affected are therefore vital to understand the roles and impacts of parasites in freshwater ecosystems (Georgiev et al. 2014).

Most studies have focused on parasites with a simple life cycle (Bouzid et al. 2008). However, many parasites have a more complex life history. The maintenance and evolution of such parasites in an ecosystem depends on the existence of potential hosts for their survival and the fulfillment of their life cycle (Bouzid-Lamine 2008). For example, the tapeworm Ligula intestinalis (Linnaeus, 1758) (Cestoda: Diphyllobothriidea) is a common and widespread parasite with a life cycle comprising three hosts. Its life cycle includes a copepod and a fish as intermediate hosts, and a piscivorous bird, in which the parasite reaches sexual maturity, serving as the definitive host (Kennedy et al. 2001; Loot et al. 2001; Bouzid et al. 2008; Hoole et al. 2010; Kroupova et al. 2012). Tapeworms of the L. intestinalis species complex infect a large range of freshwater Cyprinidae (Bouzid et al. 2013), and are widespread throughout the northern hemisphere (Dubinina 1980). It has been recorded from the body cavity of, among others, roach, Rutilus rutilus (Kennedy et al. 2001; Loot et al. 2002), straightfin barb, Barbus paludinosus (Barson and Marshall 2003), tench, Tinca tinca (Korkmaz and Zencir 2009) and Chalcalburnus mossulensis (Parsa Khanghah et al. 2011). L. intestinalis has also been shown to impact on the growth of the host fish (Loot et al. 2002), and has considerable potential to impact on gonad development of its host (Kennedy et al. 2001, Jobling and Tyler 2003).

In this study, we investigate the dynamics of an epizootic of L. intestinalis (hereafter called simply Ligula) in the Hamiz reservoir (hereafter Hamiz). Hamiz is one of the oldest Algerian dams, dating back to 1869. Its waters are used for irrigation and for drinking. The most common fish in the Hamiz, and the only native species, is the Algerian barb, Barbus callensis Valenciennes, 1842 (Froese and Pauly 2014).This Least Concern (LC) barbel species (García et al. 2010) is endemic to the Maghreb and widely distributed in the running waters (Lévêque and Daget 1984) that originate in the Atlas Mountains. The presence of barbels tends to indicate fluvial habitats of relatively low disturbance (Britton and Pegg 2011). However, this species has also adapted to life in the littoral of reservoirs. Several other non-native fish species also occur in the Hamiz, including the invasive common carp Cyprinus carpio
Linnaeus, 1758, silver carp Hypophthalmichthys molitrix (Valenciennes, 1844) and bighead carp Hypophthalmichthys nobilis (Richardson, 1845), which were imported from Hungary (Ministry of Fisheries and Aquaculture). These Cyprinids are among the most frequently introduced species (Froese and Pauly 2014) and are considered as potentially harmful (IUCN 2014). Moreover, these species have been shown to be potential hosts for the Ligula parasite (Vulpe 2002, Urdeş and Hangan 2013) and prior to their introduction Ligula infection of $B$. callensis was never reported on this lake.

We had three main objectives. First, we assessed the potential and actual occurrence of Ligula infestation in the Hamiz by quantifying the infection of native fish over multiple years and evaluating the presence of other life stage hosts. Second, we examined the dynamics and effects of this infection. In common with Ligula populations in other areas (Korkmaz and Zencir 2009; Loot et al. 2002), we predicted that Ligula population dynamics and infection rate would be influenced by seasonal differences. We also predicted that, like other parasitic infections, Ligula would cause a reduction in native fish condition (Barson and Marshall 2003) and gonad weight (Carter et al. 2005; Dejen et al. 2006, Trubiroha et al. 2010). Finally, we considered the evidence in support of the hypothesis that Ligula infection has a cyclic character in the Hamiz by evaluating whether infection rate decreased, and was associated with differences in fish characteristics, over time. Based on these results and knowledge of the ecology of this cestode and its hosts, we discuss possible reasons for the dynamics of this epizootic process associated with Ligula infection in the Hamiz.

\section{Materials and Methods}

\section{Study site}

The Hamiz reservoir is built on the wadi (river) Arbatache (Fig. 1), situated in the plain of Mitidja $\left(36^{\circ} 35^{\prime} 59^{\prime \prime} \mathrm{N}\right.$, $\left.3^{\circ} 20^{\prime} 50^{\prime \prime} \mathrm{E}\right), 158 \mathrm{~m}$ above sea level and $35 \mathrm{~km}$ east of Algiers (Ould Rouis et al. 2012). The dam area has a Mediterranean climate: the period from summer until early autumn is hot and dry. The late autumn and winter are wet. Some rains persist in spring. Monthly average air temperatures vary from $12^{\circ} \mathrm{C}$ to $26^{\circ} \mathrm{C}$ and increase in April-May. The water level in Hamiz depends on rainfall, evaporation and the use of water for irrigation, all of which leads to a level range of $13 \mathrm{~m}$. Precipitation averages $839.4 \mathrm{~mm}$ per annum, but is variable.

\section{Fish data}

Monthly sampling was conducted in the Hamiz from October 2005 to February 2008, with the exceptions of February 2006 and August 2006 and 2007. Further intermittent surveys were carried out until 2010. Two $50 \times 1.5 \mathrm{~m}$ 3-layered trammel nets with inner net mesh size of $15 \mathrm{~mm}$ and $20 \mathrm{~mm}$ and outer net 


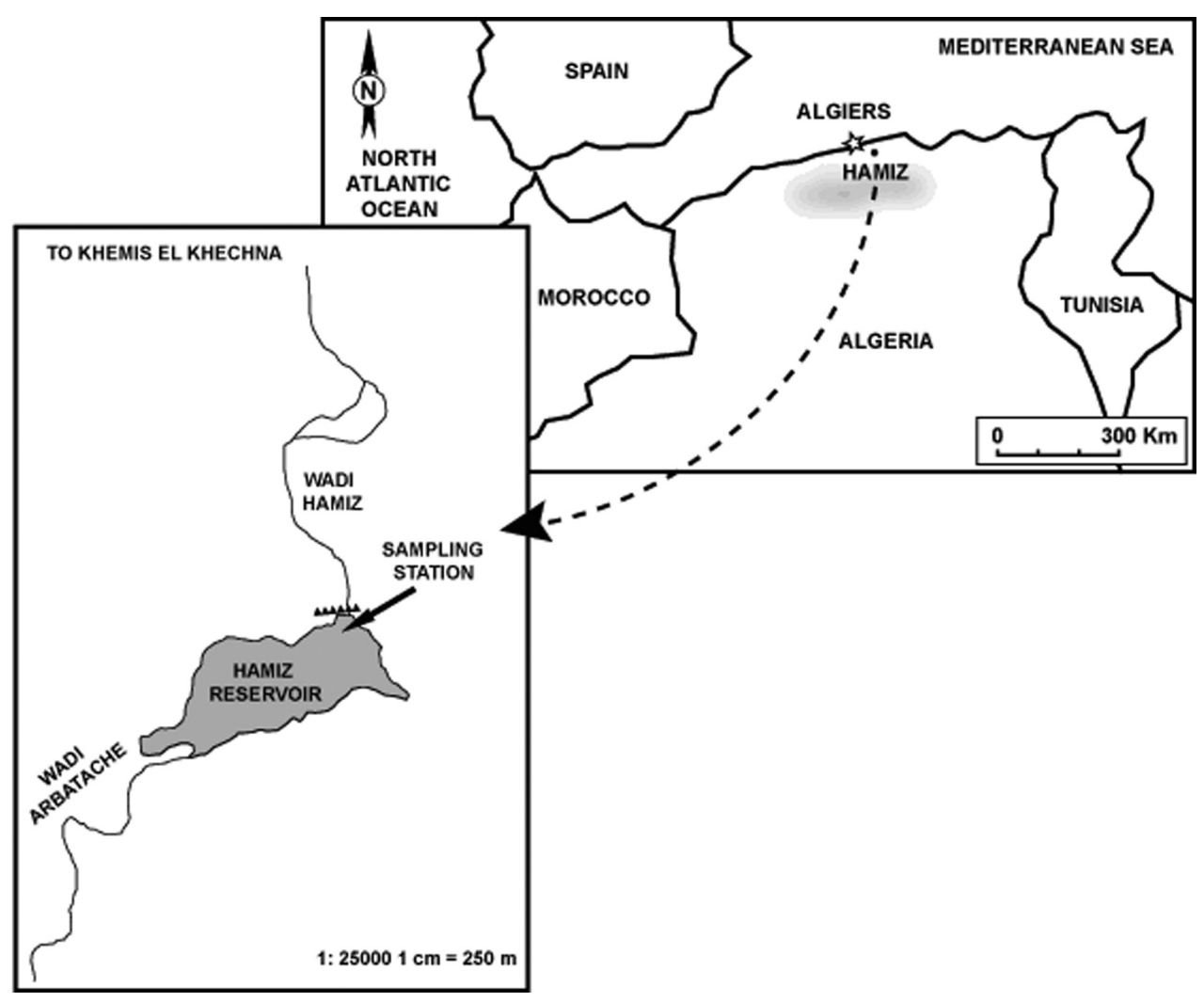

Fig. 1. Hamiz and location of the sampling station on the reservoir

mesh size of $155 \mathrm{~mm}$ and were deployed in the morning, in the deepest area of the lake, and left submersed in water overnight. The next morning, the nets were removed from the water and all fish were collected and sacrificed, then immediately transported in cool boxes to the laboratory.

For each fish, total (TL) and standard (SL) body length were measured to the nearest millimeter, and total weight (TW) was obtained to the nearest gram. After dissection, gutted fish were weighed (somatic or eviscerated weight). Viscera and gonads were separated and each was weighed to the nearest $0.001 \mathrm{~g}$. Observation of gonad state allowed us to separate fish into mature males and females and immature fish.

\section{Parasite collection}

Fish were classified according to the presence or absence of plerocercoid larvae as infected and uninfected fish, respectively. When parasites were present, they were removed from the abdominal cavity, numbered and individually weighed $(\mathrm{Wp})$ to the nearest $0.001 \mathrm{~g}$ and then preserved in $95 \%$ ethanol. These samples were used for genetic analysis by W. BouzidLamine.

\section{Bird and zooplankton hosts}

Observations and counts of waterbirds were also conducted from October 05 to October 06, with occasional surveys thereafter, to assess the availability of avian hosts. We made standardized visual observations with binoculars from a vehicle running at a low constant speed along a predetermined trajectory in less than three hours, excluding extreme weather conditions.

To determine the copepod species that inhabit the lake, surface and vertical samples were collected using a plankton net of $100 \mu \mathrm{m}$ mesh size. Plankton sampling was conducted monthly around the same site as the fish samples, just before deploying the fish nets in the morning. The disturbance this entailed was no more than that required to set the fish nets, and fish had a full 24 hours to enter the fish nets after deployment, so plankton sampling should not have affected fish sampling. Plankton samples were removed from the net and fixed in $4 \%$ formaldehyde solution for laboratory analysis. Individuals were identified to species level using a compound microscope (Zeiss) at high power magnifications with particular attention to copepods, the intermediate hosts of Ligula. Taxonomic identifications of copepods were performed according to Dussart $(1967,1969)$.

\section{Statistical analysis}

Analyses were conducted in three stages: First, we assessed whether Ligula infection is affected by seasonal factors. Second, we characterized the effects of the parasite on Algerian barbs. For these two sets of analyses we used the data recorded between October 2005 and October 2006. Third, we charac- 
terized the infection using data from all surveys. Statistical analyses were performed using the software package IBMSPSS/ v. 20.

\section{Seasonality of Ligula intestinalis infection}

To test the hypothesis that parasitization shows seasonality, we first calculated the parasitization index (PI: Equation 1) (Kennedy and Burrough 1981) for each infected fish $(\mathrm{n}=22)$; then the prevalence (P: Equation 2), abundance (A: Equation 3 ) and intensity (I: Equation 4) of parasites for each month (Bush et al. 1997, Margolis et al. 1982). These infection parameters were calculated using the program Quantitative Parasitology (Reiczigel and Rózsa 2005).

Equation 1:

$P(\%)=\frac{W_{p}}{\mathrm{TW}-\mathrm{W}_{\mathrm{p}}} \times 100$

$\mathrm{W}_{\mathrm{p}}=$ the total weight of parasites per host; $\mathrm{TW}=$ total host weight.

Equation 2:

$P(\%)=\frac{N^{\prime}}{H} \times 100$

$\mathrm{N}^{\prime}=$ the number of hosts infected with the parasite $L$. in testinnalis; $\mathrm{H}=$ the number of hosts examined for the parasite species.

Equation 3:

$A=\frac{n_{p}}{H}$

$n_{\mathrm{p}}=$ the total number of individual parasite across all hosts;

$\mathrm{H}=$ the total number of potential hosts examined (infected and uninfected).

Equation 4:

$I=\frac{n_{p}}{N^{\prime}}$

$n_{p}=$ the total number of individual parasite across all hosts; $\mathrm{N}^{\prime}=$ the number of hosts infected with $L$. intestinalis.

Each of these variables was used as the dependent variable in separate Generalized Linear Models (GLMs), assuming normal distribution with an identity link function. For the prevalence, abundance and intensity of parasitic infection, season was the independent variable (spring: March to May; summer: June to August; autumn: September to November; and winter: December to February). For parasitic index, in addition to season, fish sex was included as an independent variable as males and females are likely to be differentially affected by season. Any insignificant interaction term was removed and the analysis repeated to obtain the simplest model.

\section{Characterization of Ligula intestinalis infection in Algerian barbs}

To assess whether the incidence of infection was sex, ontogenetic stage or size dependent, we conducted two analyses. First, we calculated the proportion of the total fish catch that were infected for each of males, females and juveniles and used this as the dependent variable in a $\chi^{2}$ test. Second, using data for all fish $(n=434)$ we conducted a GLM with infection as the dependent variable (yes/no: binomial distribution, logit link function) and fish standard length as the independent variable. We further assessed whether larger fish contain more parasites using two correlations: fish standard length (SL) versus each of parasite number and parasite weight. For the correlations, we used only infected fish for which parasite weight was available ( $\mathrm{n}=19)$. As both SL and parasite weight were normally distributed we used a Pearson correlation for this analysis and a Spearman correlation for the non-normal parasite number.

Then, we investigated the effects of parasitic infection on Algerian barbs. First, to test the hypothesis that parasite infection causes a reduction in fish condition, we calculated a condition factor (e.g. Nash et al. 2006) for each fish (Equation 5) and used this as the independent variable in a GLM with normal distribution and identity link function. The independent variables were infection, which was our main interest, and season and sex, both of which are likely to affect fish condition. These were first included in a fully factorial analysis, then to obtain the simplest model the analysis was repeated with insignificant interaction terms removed.

Equation 5:

$\mathrm{K}=100 W L^{-3}$

$\mathrm{W}=$ total weight $(\mathrm{g})$ for uninfected fish and for infected fish, $\mathrm{W}=$ total weight less the parasite weight; $\mathrm{L}=$ standard length $(\mathrm{cm})$.

Second, we assessed the hypothesis that infected fish have reduced gonad weight. For this analysis we used all adult fish for which gonad weight was recorded $(n=316)$ in a GLM with gonad weight as the dependent variable (normal distribution, identity link function), and infection (our main variable of interest), season and sex (likely influences on gonad weight) as interacting independent variables. Total weight was included in the model as a covariate. As before, the analysis was repeated with any insignificant interaction terms removed to obtain the simplest model. 
Finally, we investigated the hypothesis that gonad weight is reduced in direct proportion to parasite weight. While it is not possible to assess the reduction in gonad weight caused by parasite infection, a correlation between gonad weight and parasite weight gives indirect evidence for such an influence. We therefore conducted a Pearson correlation (as both variables were normally distributed) on gonad weight versus parasite weight.

\section{Characterization of Ligula intestinalis infection}

To test the hypothesis that L. intestinalis infection in the Hamiz was in decline, we first calculated the proportion of fish infected out of the total fish caught for all months for years 1 and 2. Year 3 was incomplete so was not included. As these data did not approximate normality or Poisson (or other distributions) they were used as the dependent variable in a Wilcoxon signed rank test with year as the independent variable.

We also assessed whether infection was associated with differences in fish characteristics over time. We conducted separate Generalized Estimating Equations (GEEs: an extension of GLMs for use when data is non-independent) with each of number of fish caught per month; and fish standard length, weight and condition factor (calculated using Equation 5 above) as the dependent variables (normal distribution, identity link function). Year was the within subjects factor and year, season and their interaction were the independent variables in the final model.

\section{Results}

The most common fish in Hamiz was $B$. callensis, of which 434 specimens were collected in the first year. Females were more numerous and larger (Fig.2a) than males (Fig.2b) and juveniles were present in our samples (Fig.2c). In total 57 plerocercoids (three parasites on average per infested fish) were recorded from 22 fish. The minimum and maximum parasite weights were $0.12 \mathrm{~g}$ and $6.3 \mathrm{~g}$ with average $2.0 \mathrm{~g}$. The greatest number of parasites harbored by a single infected fish was 8 . Two fish had five, one had four and the remainder had between one and three parasites in the abdominal cavity.

After January 2007 and until February 2008, the annual number of $B$. callensis caught dropped sharply to 132 specimens, none of which were parasitized. Irregular surveys continuing into 2010 showed the same picture: not a single infected fish was found.

\section{Estimation of bird and zooplankton species}

During our main survey, five waterbird species were observed on the lake (Fig.3): the Great-crested Grebe, Podiceps cristatus; the Little Grebe, Tachybaptus ruficollis; the Mallard, Anas platyrhynchos; the Red-knobbed Coot, Fulica cristata; and the Great Cormorant, Phalacrocorax carbo. Additionally, in later surveys, we noted the Western Great Egret, Ardea alba (Linnaeus, 1758), the Grey Heron, Ardea cinerea (Linnaeus, 1758) and the Eurasian Wigeon, Mareca penelope Linneaus, 1758 (Avibase 2014). The two grebe species and the mallard are widespread breeding species in Algeria, while the egret and coot are localised breeders (Samraoui and Samraoui 2008) and the cormorant and heron

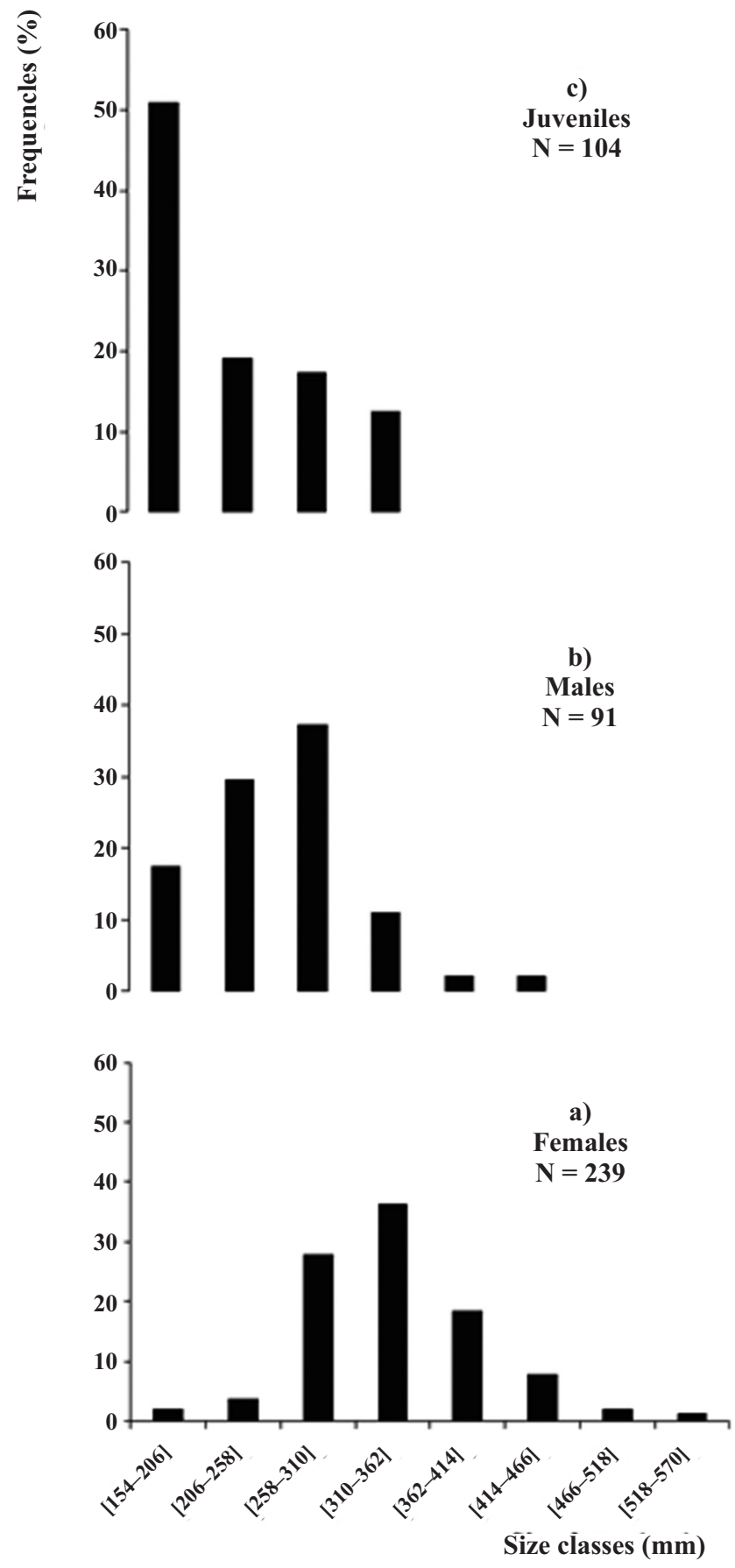

Fig. 2. Frequency of barbels in relation to size classes during year 1: a) females, b) males and c) juveniles 


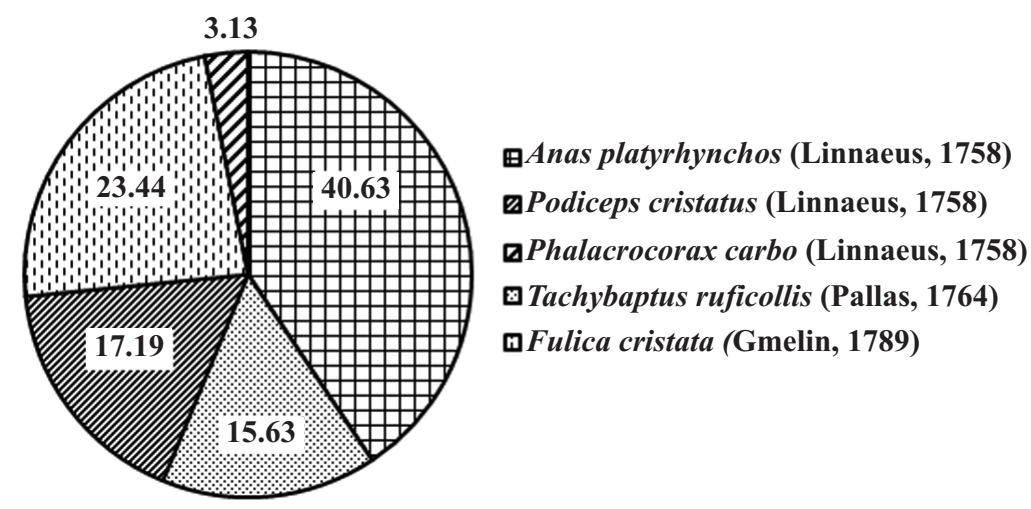

Fig. 3. Proportions of waterbird species observed on the Lake (From October 05 to October 06)

are highly dispersed migrant species. Of these species, the cormorant, heron and Great Crested Grebe are known to be potential final hosts for L. intestinalis (Loot et al. 2001). However, none of the piscivorous species (both grebes, heron, cormorant and egret) were encountered very frequently.

The zooplankton community decreased in abundance in winter, but stocks remained appreciable. The cladocerans included three species of Daphnia while the copepods, the first intermediate host, were dominated by Copidodiaptomus numidicus (Gurney, 1909) with fewer Acanthocyclops americanus (Marsh, 1893) and Cyclops abyssorum G.O. Sars, 1863. The latter two copepods have a wide geographic range whereas the former is endemic to the Maghreb and southern Iberia (Dumont 1979).

\section{Seasonality of Ligula intestinalis infection}

The parasitization index of infected fish ranged from 0.00 to 3.33 with an average of 1.48 . This differed significantly with season (Wald $\chi^{2}=11.338, \mathrm{df}=3, \mathrm{p}=0.010$ ), from the lowest value in summer to the highest in winter (Fig.4), but note that the winter sample contained only one infected fish. PI did not differ with sex (Wald $\chi^{2}=5.337, \mathrm{df}=2, \mathrm{p}=0.069$ ) and the interaction between these variables was insignificant (Wald $\chi^{2}=$ $5.177, \mathrm{df}=3, \mathrm{p}=0.159)$. Once this interaction was removed, neither variable produced a significant difference in parasitic index (season: Wald $\chi^{2}=5.988, \mathrm{df}=3, \mathrm{p}=0.112$; sex: Wald $\chi^{2}$ $=5.526, \mathrm{df}=3, \mathrm{p}=0.063)$.

The average prevalence across the whole study was $5.07 \%$. No infection was recorded in November, January and April, although the maximum number of parasites collected (27) was in spring. Prevalence was lowest in winter $(1.20 \%)$ and increased in summer $(8.06 \%)$, whereas mean abundance and mean intensity were marked by spring peaks ( 0.19 and 2.4 respectively). However, there were no significant seasonal differences for any of the epidemiological parameters (Prevalence: Wald $\chi 2=3.166, \mathrm{df}=3, \mathrm{p}=0.367$; Abundance: Wald $\chi^{2}=3.846, \mathrm{df}=3, \mathrm{p}=0.279$; Intensity: Wald $\chi 2=1.849, \mathrm{df}=3, \mathrm{p}=0.64)$.

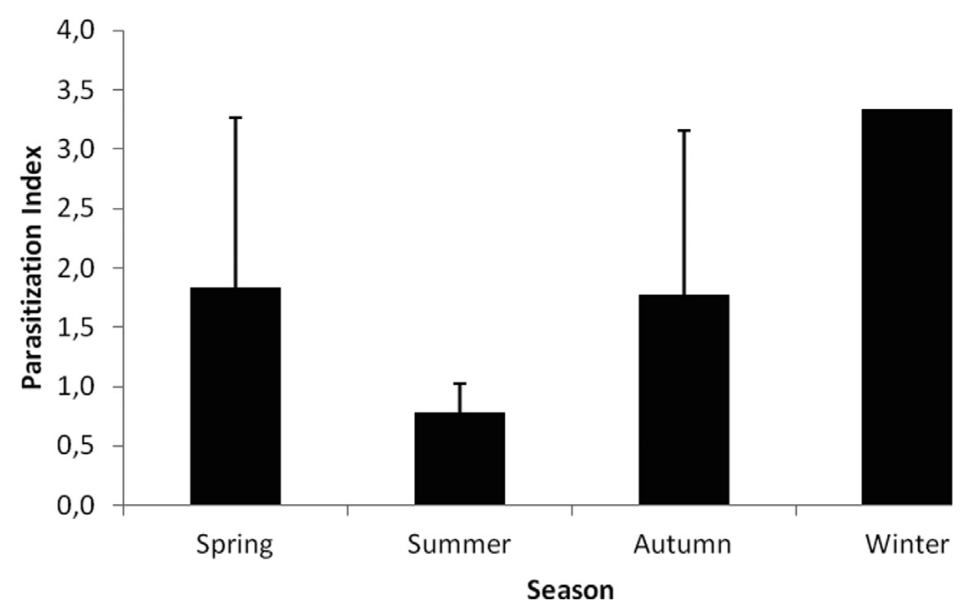

Fig. 4. Mean parasitization index for all infected fish per season, from October 05 to October 06. Error bars show standard deviation. Note that the winter sample contained only one infected fish so has no measure of dispersion 
Table I. Results from the GLM of the effects of infection on fish condition. Analysis 1: factorial analysis; Analysis 2: interaction terms removed

\begin{tabular}{|c|c|c|c|}
\hline Analyses & Wald $\chi^{2}$ & df & $\mathbf{p}$ \\
\hline \multicolumn{4}{|c|}{ Analysis 1: Factorial } \\
\hline Infection (I) & 0.048 & 1 & 0.826 \\
\hline Season $(\mathrm{Se})$ & 0.080 & 3 & 0.993 \\
\hline $\operatorname{Sex}(\mathrm{Sx})$ & 0.060 & 2 & 0.971 \\
\hline $\mathrm{I} \times \mathrm{Se}$ & 0.052 & 3 & 0.997 \\
\hline $\mathrm{I} \times \mathrm{Sx}$ & 0.093 & 2 & 0.954 \\
\hline $\mathrm{Se} \times \mathrm{Sx}$ & 0.477 & 6 & 0.998 \\
\hline $\mathrm{I} \times \mathrm{Se} \times \mathrm{Sx}$ & 0.060 & 3 & 0.996 \\
\hline
\end{tabular}

Analysis 2: Main effects

\begin{tabular}{llll}
\hline Infection & 0.380 & 1 & 0.538 \\
Season & 4.141 & 3 & 0.247 \\
Sex & 2.866 & 2 & 0.239 \\
\hline
\end{tabular}

\section{Characterization of Ligula intestinalis infection in Algerian} barbs

There was no difference in the frequency of infection with sex or ontogenetic stage $(\chi 2<0.001, d f=2, p=1.000)$. However, uninfected fish were significantly smaller than infected fish (Wald $\chi^{2}=7.806, \mathrm{df}=1, \mathrm{p}=0.005$; Fig.5). For those fish that were infected, neither parasite weight (Pearson $\mathrm{r}=$ $0.328, \mathrm{n}=19, \mathrm{p}=0.170$ ) nor parasite number (Spearman $\mathrm{r}$ $=0.215, \mathrm{n}=19, \mathrm{p}=0.377$ ) was significantly correlated with fish size.

There was no obvious difference in weight: total weight ranged between $33 \mathrm{~g}$ and $2231 \mathrm{~g}$ in uninfected fish, and $63 \mathrm{~g}$ and

Table II. Results from the GLM of the effects of infection on gonad weight. Analysis 1: factorial analysis; Analysis 2: interaction terms removed. Significant results are highlighted in bold

\begin{tabular}{lccc}
\hline \multicolumn{1}{c}{ Analyses } & Wald $\boldsymbol{\chi}^{\mathbf{2}}$ & df & p \\
\hline \multicolumn{4}{l}{ Analysis 1: Factorial } \\
\hline Infection (I) & 6.626 & 1 & $\mathbf{0 . 0 1 0}$ \\
Season (Se) & 4.519 & 3 & 0.211 \\
Sex (Sx) & 0.033 & 1 & 0.857 \\
$\mathrm{I} \times \mathrm{Se}$ & 1.902 & 2 & 0.386 \\
$\mathrm{I} \times \mathrm{Sx}$ & 0.287 & 1 & 0.592 \\
$\mathrm{Se} \times \mathrm{Sx}$ & 0.941 & 3 & 0.816 \\
$\mathrm{I} \times \mathrm{Se} \times$ Sx & 0.308 & 2 & 0.857 \\
Total Weight & 212.471 & 1 & $<\mathbf{0 . 0 0 1}$ \\
\hline Analysis 2: Main effects & & \\
\hline Infection & 9.605 & 1 & $\mathbf{0 . 0 0 2}$ \\
Season & 54.013 & 3 & \\
Sex & 1.167 & 1 & 0.280 \\
Total Weight & 205.158 & 1 & $<\mathbf{0 . 0 0 1}$ \\
\hline
\end{tabular}

$2050 \mathrm{~g}$ in infected fish. This similarity is reflected in the results for condition factor, which was not influenced by any of infection, season or sex, and nor were any of the interaction terms significant (Table I, Analysis 1). Removing the interaction term still failed to produce a significant effect (Table I, Analysis 2).

The effect of the parasite infection was clearly observed in gonad size, which increased with fish total weight (Table II; Fig.6). Gonads were normally developed in uninfected fish (mean weight $6.67 \mathrm{~g} \pm 12.26$ ), but significantly atrophied (mean weight $4.90 \mathrm{~g} \pm 12.55$ ) in infected ones. All other variables and their interactions were insignificant (Table II, Analysis 1). When the interaction terms were removed, all of infection, season and total weight significantly affected gonad weight (Table II, Analysis 2) but sex remained insignificant. Gonad weight increased with total weight for both uninfected and infected fish in spring (Fig.6a), whereas in summer (Fig.6b) and autumn (Fig.6c) uninfected fish showed a similar increase in gonad weight with total weight, while for infected fish gonad size was approximately the same for fish of all sizes. However, there was no correlation between gonad weight and parasite weight (Pearson $\mathrm{r}=0.219, \mathrm{n}=15, \mathrm{p}=0.434$ ).

\section{Characterization of Ligula intestinalis infection}

The proportion of infected fish caught was significantly higher in year $1(Z=-2.197, n=24, p=0.028$; Fig.7). In year 2 infected fish were caught only in the autumn and infection col-

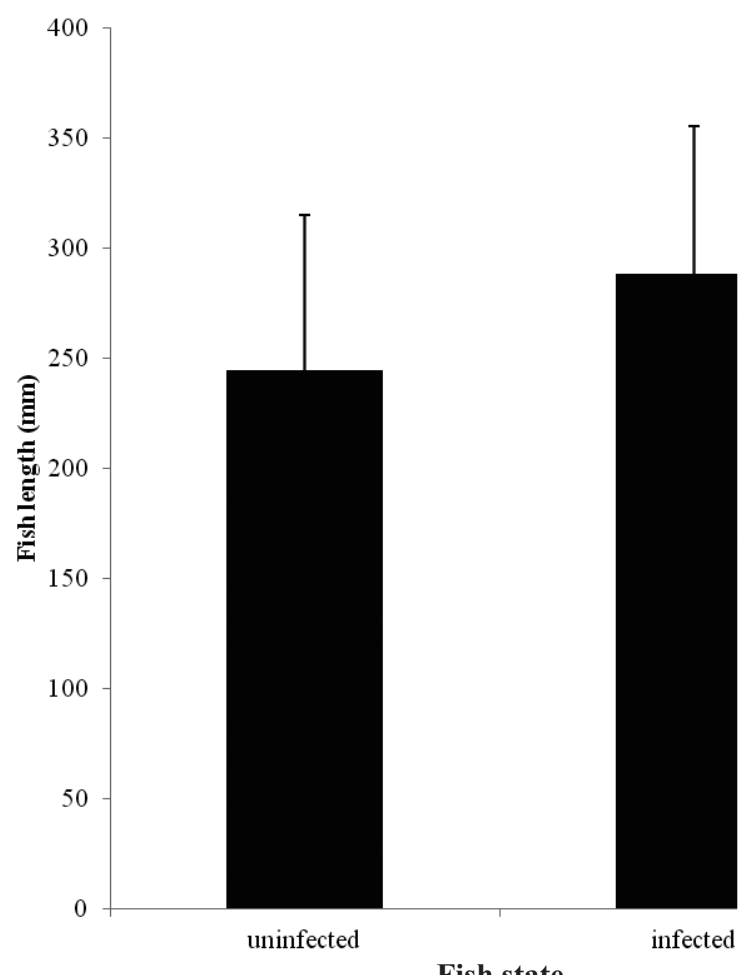

Fig. 5. Mean standard length of uninfected and infected fish pooled for each group. Error bars show standard deviation 

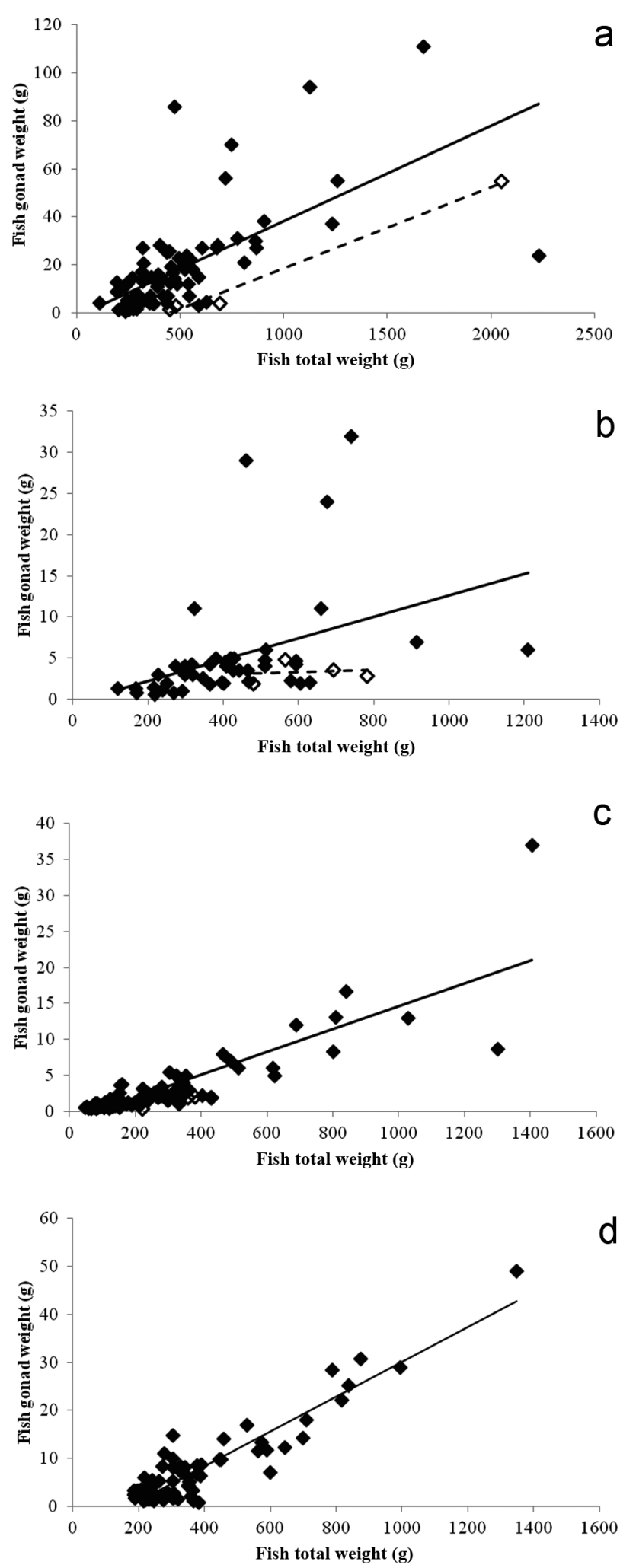

Fig. 6. Differences between gonad weight of uninfected (black diamonds, solid line) and infected (white diamonds, dashed line) fish pooled per season of year 1: a) spring, b) summer, c) autumn, d) winter. Note: In the autumn graph (c), the infected fish data is obscured by the uninfected fish data while for the winter graph (d) no infected fish were used in the analyses

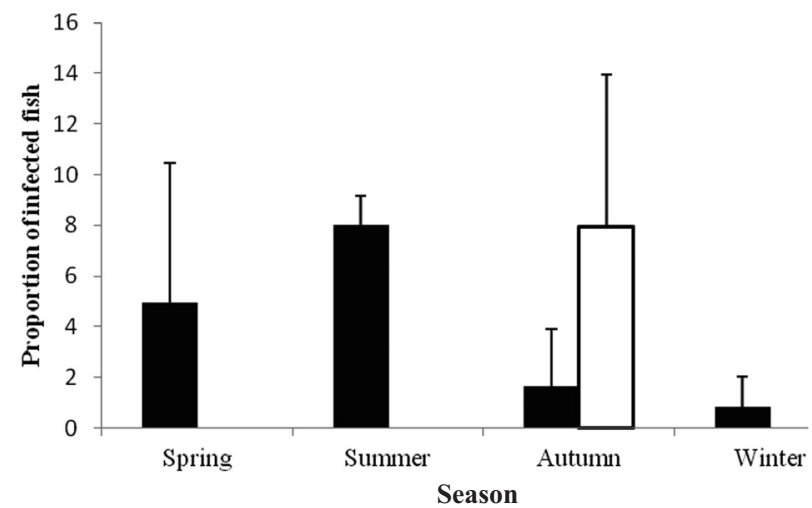

Fig. 7. Mean proportion of infected fish caught by season and year. Black bars: Year 1 (October 05 - September 06); white bars: Year 2 (October 06 - September 07). Error bars represent standard deviation

lapsed to zero by the second winter of our survey (Fig.7). This is associated with differences in demographic parameters. In year 1 the number of fish caught was fairly constant across seasons (Fig.8a). In year 2, fish catch was significantly reduced compared to year 1 (Table III, Analysis 1), with the exception of autumn in which fish catch was much higher (Fig.8a). By year 3 the number of fish caught was reduced dramatically (Table III, Analysis 1; Fig.8a). Standard length (Fig.8b) and total weight (Fig.8c) show some similar patterns across years and seasons (Table III, Analysis 2 and 3). For both variables, the lowest values were in autumn (Figs.8b and 8c). Year 2 values were lower than year 1 in spring and summer for length (Fig.8b), and in all seasons for weight (Fig.8c). How-

Table III. Results from the GEE for: Analysis 1: number of fish caught; Analysis 2: differences in standard length; Analysis 3: differences in weight; Analysis 4: differences in condition factor. Significant results are highlighted in bold

\begin{tabular}{llll}
\hline Analyses & Wald $\chi^{2}$ & df & p
\end{tabular}

Analysis 1: Number of fish caught

\begin{tabular}{llll}
\hline Year & 13.319 & 2 & $\mathbf{0 . 0 0 1}$ \\
Season & 13.685 & 3 & $\mathbf{0 . 0 0 3}$ \\
Year x Season & 14.436 & 4 & $\mathbf{0 . 0 0 6}$
\end{tabular}

Analysis 2: Standard length

\begin{tabular}{lccc} 
Year & 6.185 & 2 & $\mathbf{0 . 0 4 5}$ \\
Season & 70.306 & 3 & $<\mathbf{0 . 0 0 1}$ \\
Year x Season & 11.820 & 4 & $\mathbf{0 . 0 1 9}$ \\
\hline Analysis 3: Weight & & & \\
\hline Year & 8.610 & 2 & $\mathbf{0 . 0 1 4}$ \\
Season & 64.289 & 3 & $<\mathbf{0 . 0 0 1}$ \\
Year x Season & 6.342 & 4 & 0.175
\end{tabular}

Analysis 4: Condition factor

\begin{tabular}{llll}
\hline Year & 2.637 & 2 & 0.268 \\
Season & 7.254 & 3 & 0.064 \\
Year x Season & 5.740 & 4 & 0.219 \\
\hline
\end{tabular}



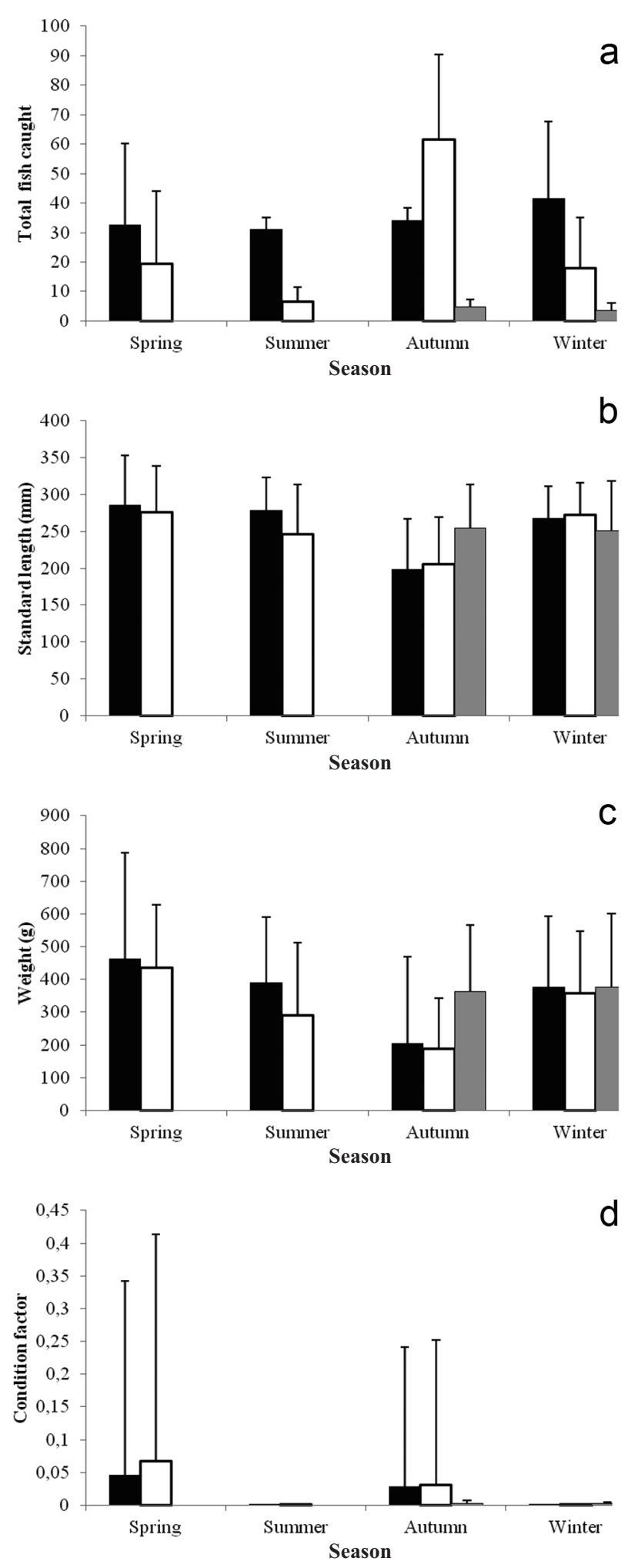

Fig. 8. Changes by season and year of: a) mean number of fish caught, b) mean standard length of fish caught, c) mean weight of fish caught, d) mean condition factor of fish caught. Black bars: Year 1 (October 05 - September 06); white bars: Year 2 (October 06 - September 07); grey bars: Year 3 (October 07 - February 08). Error bars represent standard deviation ever, autumn and winter values for length were higher in year 2 (Fig.8b). Fish showed an apparent recovery in year 3, with higher values for both length and weight (Figs.8b and 8c). However, parasite infection still did not significantly affect host condition factor (Table III, Analysis 4; Fig.8d).

\section{Discussion}

Barbus callensis in the Hamiz reservoir were infected with Ligula intestinalis, particularly during our earlier sampling, thus confirming the presence of the parasite in this region where it had previously not been recorded. For a Ligula population to perpetuate itself, the three stages in its life cycle should be approximately equally successful: copepods are the first intermediate host, fish are the second, and piscivorous birds are the final host in which the parasite reaches sexual maturity. Although the adult worm has a lifespan of only few days inside their definitive host (Kennedy et al. 2001), these fish-feeding migrants play a crucial role in the life cycle of Ligula (Loot et al. 2001). Three potential bird hosts, the cormorant, heron and great crested grebe, were found at the Hamiz during our surveys. Of these, the cormorant and heron are migrant species so may be implicated in the introduction of Ligula into the Hamiz. However, all three species were relatively uncommon, probably because of the lack of quality habitats which are closely associated with the aquatic environment (Samraoui et al. 2011), so their role in this introduction and subsequent dispersal within the lake is likely to be negligible. The first intermediate copepod host plays an equally important role in the infection chain (Loot et al. 2001). If no appropriate copepod species is available, the parasite cycle cannot be closed (Piasecki et al. 2004). However, not all copepods are equally susceptible to coracidia (Loot et al. 2001). Copepodid stages are immune from infection, while carnivorous adults consume tapeworm larvae instead of being parasitized by them and therefore constrain rather than promote tapeworm success. In Hamiz, two of the three species (Cylops abyssorum and Acanthocyclops americanus) are carnivores, and only Copidodiaptomus numidicus, a westMediterranean endemic and the most abundant copepod species in the Hamiz, is a particle-eater and perhaps a suitable host. Therefore, although non-fish hosts are limited to a few species only, their presence should allow the Ligula infection in the Hamiz to persist.

Transmission of infection from the copepod to the fish host depends on the ability of the fish to predate the invertebrate. The $B$. callensis population in the Hamiz appeared well adapted with numerous females. During the spawning season, when the temperature rises between April and May, mature females and males come into contact, and juveniles appear in the lake in summer particularly on its shores (Ould Rouis, personal observation). At this stage, barbels may feed on zooplankton, thus potentially causing infection with the parasitic tapeworm, and our results showed a highest prevalence during 
the dry summer season and decreases in winter. Although seasonal effects were negligible in our study, this does suggest that summer is the time of greatest potential Ligula infection of barbel via predation of copepods. However, the feeding regime of fish plays an all-important role in transmission success (Loot et al. 2001). B. callensis are benthic feeders so in the Hamiz parasite larvae were confronted with a non-lacustrine fish that will only feed on zooplankton if given no other choice (Kraïem 1996). Moreover, as copepods are agile swimmers and therefore not easy prey for fish, they are unlikely to be consumed if easier prey species, such as cladocerans, are available. Our sampling showed the presence of at least three species of Daphnia in the Hamiz which are likely to be preferentially consumed by barbels. Nevertheless, the presence of Ligula infection in the Hamiz barbel population indicates some transfer of the parasite from the first to the second intermediate host and the infection parameters in the Hamiz are comparable with those in other areas. Values of parasitization index were close to those in Mogan Lake in Turkey (Ergonul and Altindag 2005), while the prevalence, mean intensity and abundance values were similar to those in roach and rudd in two reservoirs in Tunisia (Bahri-Sfar et al. 2010) and Straightfin barb in Zimbabwe (Barson and Marshall 2003).

Neither sex nor ontogeny affected the probability of becoming infected with Ligula. Likewise, neither parasite weight nor number were dependent on fish size. However, infected fish were significantly larger than those who were healthy. Infestation was minimal in fish sized $154-310 \mathrm{~mm}$, increased to a maximum in hosts of $414-466 \mathrm{~mm}$ and never occurred in fish larger than $466 \mathrm{~mm}$. Similar size distributions of Ligula infection have been recorded in other locations (Zhokhov and Pugacheva 2012). Only 0+ and possibly some $1+$ fish will eat zooplankton (Cherghou et al. 2002) and so become infected, indicating that these larger fish were infected when they were young and grew to the size at which they were found during our survey. The disappearance of large-sized infected hosts might occur if older fish develop immunity (Quinnell et al. 1995), but there is no evidence that infected fish can ever shake off their parasite load. Alternatively, large infected fish might have died en masse under their parasitic load (Loot et al. 2002). However, we found no evidence that such heavily infected fish were ever present in the Hamiz, where we noted a weak infection instead. Diseased fish did have inhibited gonad development, a phenomenon reported by others (Kennedy et al. 2001, Carter et al. 2005, Dejen et al. 2006, Trubiroha et al. 2010), which has been ascribed to Ligula causing hormonal disorders in fish (Jobling and Tyler 2003). Ligula may thereby regulate the size of its fish host population, but only if a sufficient number of fish are infected. At low prevalence and infection rates, it is unclear whether this parasitic castration has any tangible ecological effects. Moreover, condition factor was not influenced by infection (Msafiri et al. 2014), confirming that Ligula at low infection rates is relatively harmless (Ergonul and Altindag 2005). This also suggests that the loss of weight of the gonad is almost exactly compensated by abundance of perivisceral fat in the fish (Trubiroha et al. 2010).

Overall, the dynamics of the Ligula infection in the Hamiz appeared to be quite weak and of a temporary nature suggesting an epizootic cycle typical of this cestode parasite (Kennedy et al. 2001, Hoole et al. 2010). The size distribution of infected fish in earlier surveys is notable in this respect, with minimal infection of smaller fish. Moreover, during our later surveys the rate of infection of barbels decreased over time until no infected fish were found at all, and the fish population showed some recovery in both the length and weight of captured animals by the third year although the total fish catch remained low compared to our initial surveys. There are several possible contributing factors to this epizootic process associated with the Ligula infection in the Hamiz. The lack of strong ecological effects of this infection is significant in this regard as this may allow stochastic environmental changes to affect parasite abundance (Yen Nhi et al. 2013). A second possibility is that Ligula infection may decline if suitable intermediate hosts are lacking so the parasitic life cycle is not closed (Loot et al. 2001, Bouzid-Lamine 2008). Our surveys indicate that at least some hosts for all stages of the Ligula life cycle can be found in the Hamiz. However, it is still feasible that the frequency of fish (or other) hosts is reduced below the carrying capacity of the parasite population (Kennedy et al. 2001). Fish developing immunity to Ligula infection (Quinnell et al. 1995) is unlikely in this case, as there is little evidence for this possibility, but the number of barbel caught had certainly decreased by our later surveys suggesting that fish density could be a contributory factor. The specific genetic strain of Ligula may also contribute to its success or failure. Local adaptation over time tends to result in host specificity; the tapeworm parasitizes only one or few local species of fish per geographic area (Bouzid-Lamine 2008, Britton et al. 2009). North African Ligula populations generally fall into two distinct clades: the Tunisian population is related to European groups, while the Hamiz sample clustered with Chinese populations, which are highly host-specific. The Hamiz sample contrasts with that from Tunisia in which no specimens of B. callensis were infected (Kraïem 1994, Bouzid-Lamine 2008). The invasive carp species, which were introduced in 2006 for aquaculture purposes as well as to clean the dam and oxygenate the water (Ministry of Fishing and Fishery Resources), may also show differences in infection rate. In Turkey, no infection was observed in C. carpio (Turgut et al. 2011) while in the Hamiz there was a clear difference with common carp being heavily infected and silver and bighead carps not at all (Ould Rouis, unpublished data). Invasive carp may also contribute to the reduction in barbel density. The rapid increase in carp density in the dam resulted in considerable habitat alteration, including the destruction of barbel's spawning habitat, and may have promoted a reduction in the numbers of overwintering birds using the lake (Crivelli 1992). The consequent reduction in potential host numbers is likely to have impacted on parasite fitness. Thus, the introduction of carp, which is a 
likely route of unintentional Ligula introduction (Lafferty et al. 2010), and may contribute to its spread in any given area, may ironically also be influential in the decline of this Ligula infection in the Hamiz. A similar scenario has been reported in other aquatic communities (e.g. Kennedy et al. 2001).

In conclusion, we here confirm an infection of Ligula intestinalis in the Hamiz dam, a location in which Ligula has not previous been recorded. Ligula in the Hamiz exhibited weak ecological effects in native fish species and, in common with other aquatic systems, probably showed an epizootic cycle, thus declining or even failing during our study period. Likely routes of infection are through the introduction of alien carp or via migratory bird species, while of the many potential factors in its decline, alien fish species appear to be influential. Along with other authors (e.g. Hoole et al. 2010) we also highlight Ligula's unique role as a model to study the long-term effects of parasitization on host species dynamics.

Acknowledgements - Our thanks go to the staff of Hamiz dam, for their help on the ground. We are grateful to Prof. J.C. Micha, (FUNDP/Namur, Belgium) and Dr E. Vreven, (Royal Museum for Central Africa (MRAC)/ Tervuren, Belgium) for their encouragement and support. We would like to thank an anonymous reviewer for useful suggestions that greatly improved our manuscript.

\section{References}

Avibase 2014. The World Bird Database (24 June 2003) http://avibase.bsc-eoc.org

Barber I., Daniel Hoare D., Krause J. 2000. Effects of parasites on fish behaviour: a review and evolutionary perspective. Reviews in Fish Biology and Fisheries, 10, 131-165

Barson M., Marshall B.E. 2003. The occurrence of the tapeworm, Ligula intestinalis (L.), in Barbus paludinosus from a small dam in Zimbabwe. African Journal of Aquatic Science, 28 , $75-78$

Bouzid-Lamine W. 2008. Genetic structure of Ligula intestinalis (Cestoda : Diphyllobothriidea), a parasite of freshwater fish. PhD Thesis, University of Toulouse III - Paul Sabatier, France, pp. 162. (In French)

Bouzid W., Štefka J., Bahri-Sfar L., Peter Beerli P., Loot G., Lek S., Haddaoui N., Hypša V., Tomáš Scholz T., Dkhil-Abbes T., Meddour R., Ben Hassine O.K. 2013. Pathways of cryptic invasion in a fish parasite traced using coalescent analysis and epidemiological survey. Biological Invasions, 15, 1907-1923. DOI: $10.1007 / \mathrm{s} 10530-013-0418-\mathrm{y}$

Bouzid W., Stefka J., Hypsa V., Lek S., Scholz T., Legal L., Ben Hassine O.K., Loot G. 2008. Geography and host specificity: Two forces behind the genetic structure of the freshwater fish parasite Ligula intestinalis (Cestoda: Diphyllobothriidae). International Journal for Parasitology, 38 (12), 1465-1479. DOI: 10.1016/j.ijpara.2008.03.008

Britton J.R., Pegg J. 2011. Ecology of European Barbel Barbus Barbus: Implications for River, Fishery, and Conservation Management. Reviews in Fisheries Science, 19, 321-330. DOI: 10.1080/10641262.2011.599886

Britton J.R., Jackson M.C., Harper D.M. 2009. Ligula intestinalis (Cestoda: Diphyllobothriidae) in Kenya: a field investigation into host specificity and behavioural alterations. Parasitology, 136, 1367-1373. DOI: 10.1017/S003118200999059X

Bush A.O., Lafferty K.D., Lotz J.M., Shostak A.W. 1997. Parasitology meets Ecology on its own Terms: Margolis et al. Revised. Journal of Parasitology, 83, 575-583. DOI: 10.2307/3284227

Carter V., Pierce R., Dufour S., Arme C., Hoole D. 2005. The tapeworm Ligula intestinalis (Cestoda: Pseudophyllidea) inhibits LH expression and puberty in its teleost host, Rutilus rutilus. Society for Reproduction and Fertility, 130, 939-945. DOI:10.1530/rep.1.00742

Cherghou S., Khodari M., Yaâkoubi F., Benadid M., Badri A. 2002. Contribution to the study of the diet of barbel, Barbus barbus callensis (Valenciennes, 1842) of a stream of the Middle Atlas (Morocco): wadi Boufekrane. Revue des sciences de l'eau, 15, 153-163. (In French)

Crivelli A.J. 1992. Are introduced species the right answer to the declining inland fisheries within the Mediterranean region? World Fisheries Congress, Abstract Bulletin, 143

Dejen E., Vijverberg J., Sibbing F.A. 2006. Spatial and temporal variation of cestode infection and its effects on two small barbs (Barbus humilis and B. tanapelagius) in Lake Tana, Ethiopia. Hydrobiologia , 556, 109-117. DOI: 10.1007/s10750-0051187-0

Dubinina M.N. 1980. Tapeworms, (Cestoda, Ligulidae) of the Fauna of the U.S.S.R. US Department of Commerce National Technical Information Service Springfield, USA, pp. vii +320

Dumont H.J. 1979. Limnologie van Sahara en Sahel. D Sci Thesis, University of Ghent, Belgium, pp. 557

Dunn A.M., Torchin M.E., Hatcher M.J., Kotanen P.M., Blumenthal D.M., Byers J.E., Coon Courtney A.C., Frankel V.M., Holt R.D., Hufbauer R.A., Kanarek A.R., Schierenbeck K.A., Wolfe L.M., Perkins S.E. 2012. Indirect effects of parasites in invasions. Functional Ecology, 26, 1262-1274. DOI:10.1111/ j.1365-2435.2012.02041.x

Dussart B. 1967. Copepods inland waters of Western Europe. I: calanoid and harpacticoid]. N. Boubée et Cie (eds.), Paris, pp. 1-500 (In French)

Dussart B. 1969. Copepods inland waters of Western Europe. II: Cyclopoids and biology. N. Boubée et Cie (eds.), Paris, 1-292 pp. (In French)

Ergonul M.B., Altindag A. 2005. The effects of Ligula intestinalis plerocercoids on the growth features of Tench, Tinca tinca. Turkish Journal of Veterinary and Animal Sciences, 29, $1337-1341$

Froese R., Pauly D. 2014. Fishbase. World Wide Web electronic publication. (version 06/2014). http://www.fishbase.org

García N., Cuttelod A., Abdul Malak D. (ed) 2010. The Status and Distribution of Freshwater Biodiversity in Northern Africa. Gland, Switzerland, Cambridge, UK, and Malaga, Spain: IUCN ISBN: 978-2-8317-1271-0, pp. 141

Georgiev B.B., Angelov A., Vasileva G.P., Sánchez M.I., Hortas F., Mutafchiev Y., Pankov P., Green A.J. 2014. Larval helminths in the invasive American brine shrimp Artemia franciscana throughout its annual cycle. Acta Parasitologica, 59, 000 000. DOI: $10.2478 / \mathrm{s} 11686-014-0255-\mathrm{x}$

Heins D.C., Baker J.A., Green D.M. 2011. Processes influencing the duration and decline of epizootics in Schistocephalus solidus. Journal of Parasitology 97, 371-376. DOI: 10.1645/GE-2699.1

Hoole D., Carter V., Dufour S. 2010. Ligula intestinalis (Cestoda: Pseudophyllidea): an ideal fish-metazoan parasite model? Parasitology, 137, 425-438. DOI:10.1017/S0031182010000107

IUCN 2014. The IUCN Red List of Threatened Species. Version 3.2014. www.iucnredlist.org

Jobling S., Tyler C.R. 2003. Endocrine disruption, parasites and pollutants in wild freshwater fish. Parasitology, 126, S103-S107 DOI: $10.1017 / \mathrm{S} 0031182003003652$ 
Kennedy C.R. 1993. Introductions, spread and colonization of new localities by fish helminth and crustacean parasites in the British Isles: A perspective ans appraisal. Journal of Fish Biology, 43, 287-301

Kennedy C.R., Burrough R.J. 1981. The establishment and subsequent history of a population of Ligula intestinalis in roach Rutilus rutilus (L.), Journal of Fish Biology, 19, 105-126. DOI: 10.1111/j.1095-8649.1981.tb05815.x

Kennedy C.R., Shears P.C., Shears J.A. 2001. Long-term dynamics of Ligula intestinalis and roach Rutilus rutilus: a study of three epizootic cycles over thirty-one years. Parasitology, 123, 257-269. DOI: $10.1017 /$ S0031182001008538

Korkmaz A.S., Zencir O. 2009. Annual dynamics of tapeworm, Ligula intestinalis parasitism in Tench (Tinca tinca) from Beysehir Lake, Turkey. Journal of Animal and Veterinary Advances, 8, 1790-1793

Kraïem M.M. 1994. Systematics, biogeography and bio- ecology of Barbus callensis Valenciennes, 1842 (fish, Cyprinidae) in Tunisia. PhD Thesis, Biol. Fac. Sci., Tunisia, pp. 227 (In French)

Kraiem M.M. 1996. The diet of Barbus callensis (Cyprinidae) in Northern Tunisia. Cybium, 20, 75-85

Kroupova H., Trubiroha A., Wuertz S., Frank S.N., Sures B., Kloas W. 2012. Nutritional status and gene expression along the somatotropic axis in roach (Rutilus rutilus) infected with the tapeworm Ligula intestinalis. General and Comparative Endocrinology, 177, 270-277. DOI: 10.1016/j.ygcen.2012. 04.007

Lafferty K.D., Torchin M.E., Kuris A.M. 2010. The geography of host and parasite invasions Pages 191-202 in S. Morand and B. Krasnow, eds. The Geography of Host-Parasite Interactions. Oxford University Press, Oxford, U.K

Lévêque C., Daget J. 1984. Cyprinidae. In: CLOFFA 1: Check List of the Freshwater Fishes of Africa (Dajet J., Gosse J.P. \& Thys van den Audenaerde D.F.E.), Orstom \& Tervuren: MRAC (eds.), Paris, pp. 410

Loot G., Francisco P., Santoul F., Lek S., Guegan J.F. 2001. The three hosts of the Ligula intestinalis (Cestoda) life cycle in Lavernose-Lacasse gravel pit, France. Archiv fur Hydrobiologie, $152,511-525$

Loot G., Aulagnier S., Lek S., Thomas F., Guegan J.F. 2002. Experimental demonstration of a behavioural modification in a cyprinid fish, Rutilus rutilus (L.), induced by a parasite, Ligula intestinalis (L.). Canadian Journal of Zoology, 80, 738-744

Margolis L., Esch G.W., Holmes J.C., Kuris A.M., Schad G.A. 1982. The use of ecological terms in parasitology (report of an ad hoc committee of the American Society of Parasitologists). Journal of Parasitology, 68, 131-133

Msafiri A., Kwendwa K., Nestory P.G., Alistidia M. 2014. Assessment of the effects of plerocercoid larvae of Ligula intestinalis (Cestoda) on Engraulicypris sardella (Cyprinidae) from northern Lake Nyasa/Malawi/Niasa. Aquatic Ecosystem Health \& Management, 17, 90-96. DOI: 10.1080/14634988. 2014.875444A

Nash R.D.M., Valencia A.H., Geffen A.J. 2006. The origin of Fulton's condition factor- setting the record straight. Fisheries, 31, 236-238

Ould Rouis S., Ould Rouis A., Micha J.C., Arab A. 2012. Reproductive biology of the Cyprinidae, Barbus callensis in an Algerian Dam. Tropicultura, 30 , 88-93. (In French)

Parsa Khanghah A., Mojazi Amiri B., Sharifpour I., Jalali jafari B., Motalebi A.A. 2011. Gonad tissue changes of Chalcalburnus mossulensis (Heckel, 1843) infected by Ligula intestinalis (cestoda). Iranian Journal of Fisheries Sciences, 10, 85-94

Piasecki W., Goodwin A.E., Eiras J.C., Nowak B.F. 2004. Importance of Copepoda in freshwater aquaculture. Zoological Studies, 43, 193-205

Pyšek P., Richardson D.M. 2010. Invasive Species, Environmental Change and Management, and Health. Annu. Rev. Environ. Resour., 35, 25-55. DOI: 10.1146/annurev-environ-033009095548

Quinnell R.J., Grafen A., Woolhouse M.E.J. 1995. Changes in parasite aggregation with age: a discrete infection model. Parasitology, 111, 635-644

Reiczigel J., Rózsa L. 2005. Quantitative Parasitology 3.0. Budapest, Hungary. Distributed by the authors

Richardson D.M., Pyšek P., Rejmánek M., Barbour M.G., Dane Panetta F., West C.J. 2000. Naturalization and Invasion of Alien Plants: Concepts and Definitions. Diversity and Distributions, 6, 93-107

Samraoui B., Samraoui F. 2008. An ornithological survey of Algerian wetlands: Important bird areas, Ramsar sites and threatened species. Wildfowl, 58, 71-96

Samraoui F., Alfarhan A.H., Al-Rasheid K.A.S., Samraoui B. 2011. An appraisal of the status and distribution of waterbirds of Algeria: indicators of global changes? Ardeola, 58, 137-163

Simberloff D., Rejmánek M. 2010. Encyclopedia of Biological Invasions University of California Press, pp. 792

Simberloff D., Martin J.L., Genovesi P., Maris V., Wardle D.A., Aronson J., Courchamp F., Galil B., Garcià-Berthou E., Pascal M., Pyšek P., Sousa R., Tabacchi E., Vilà M. 2013. Impacts of biological invasions: what's what and the way forward. Trends in Ecology \& Evolution, Ce Press, 28, 58-66. DOI: 10. 1016/j.tree.2012.07.013

Sitjà-Bobadilla A. 2008. Living off a fish: A trade-off between parasites and the immune system. Fish \& Shellfish Immunology, 25, 358-372. DOI: 10.1016/j.fsi.2008.03.018

Sitjà-Bobadilla A. 2009. Can Myxosporean parasites compromise fish and amphibian reproduction? Proc. R. Soc. B., 276, 28612870. DOI: $10.1098 / \mathrm{rspb} .2009 .0368$

Trubiroha A., Kroupova H., Frank S.N., Sures B., Kloas W. 2010. Inhibition of gametogenesis by the cestode Ligula intestinalis in roach (Rutilus rutilus) is attenuated under laboratory conditions. Parasitology, 138, 648-659. DOI: 10.1017/S00311 82010001514

Turgut E., Develi N., Yeşilayer N., Buhan E. 2011. Seasonal Occurrence of Ligula intestinalis infection in Cyprinids from Almus Dam Lake, Turkey. Kahramanmaras Sutcu Imam University Journal of Natural Sciences, 14, 9-11

Urdeş L., Hangan M. 2013. The Epidemiology of Ligula intestinalis (Phylum Platyhelminthes) within the Cyprinid Populations Inhabiting the Danubian Delta Area. Animal Science and Biotechnologies, 46, 273-276

Vulpe V. 2002. Parasitic invasions on fish stocks of N-E area from Moldavia. Revista Scientia Parasitologica, 3, 144-149

Yen Nhi T.T., Mohd Shazili N.A., Shaharom-Harrison F. 2013. Use of cestodes as indicator of heavy metal pollution. Experimental Parasitology, 133, 75-79. DOI: 10.1016/j.exppara.2012.10.014

Zhokhov A.E., Pugacheva M.N. 2012. Distribution and occurrence of Ligula intestinalis (L.) Plerocercoids (Cestoda, Ligulidae) in the fishes of Lake Tana, Ethiopia. Inland Water Biology, 5, 293-298. DOI: 10.1134/S1995082912020162 